\title{
BIOCONVERSION OF CITROFORTUNELLA MICROCARPA FRUIT WASTE INTO LACTIC ACID BY LACTOBACILLUS PLANTARUM
}

\author{
Cesar V. Ortinero',2, Alissandra Pauline B. Mariano' ${ }^{1}$, Sofronio P. Kalaw³, Rosalie R. Rafael ${ }^{2}$ \\ 1 Department of Environmental Science, Central Luzon State University, Science City of Muñoz 3120, Nueva \\ Ecija, Philippines, e-mail: cvortinero@clsu.edu.ph \\ 2 Department of Chemistry, Central Luzon State University, Science City of Muñoz 3120, Nueva Ecija, Philippines \\ ${ }^{3}$ Department of Biological Sciences, Central Luzon State University, Science City of Muñoz 3120, \\ Nueva Ecija, Philippines
}

Received: 2017.04.25

Accepted: 2017.06.01

Published: 2017.07.01

\begin{abstract}
The processing of Citrofortunella mircocarpa fruit juice generates large volume of solid waste, causing disposal problem. Several studies have demonstrated that wastes from agricultural and food processing industries such as fruit and vegetable peels contain high amount of polysaccharides that can be transformed into useful chemicals, including lactic acid, through fermentation. Lactic acid is widely used in various industries, such as in the manufacture of biodegradable plastic, and the demand for this chemical justifies the search of renewable feedstock for its biotechnological production. This study aimed to produce lactic acid from $C$. microcarpa fruit waste biomass through fermentation with Lactobacillus plantarum. The hydrolysate from C. microcarpa fruit waste was prepared, inoculated with different amounts of L. plantarum cell suspension, and incubated for three days. Lactic acid production was monitored daily. The lactic acid produced from the fermentation was recovered as calcium lactate and lactic acid crystals. The identity of the crystals was evaluated using Fourier transform infrared spectroscopy (FTIR) spectroscopy and paper chromatography. The highest lactic acid production was observed in fermentation mixtures containing the highest number of $L$. plantarum cells. Within three days of fermentation, the amount of lactic acid production increased with increasing period of incubation. Partial characterization of the crystals recovered from the fermentation mixtures by FTIR spectroscopy showed that the peaks in the spectrum were consistent with the chemical structure of lactate. Paper chromatography results likewise confirmed that the crystals are lactate. C. microcarpa fruit waste can afford lactic acid when fermented with L. plantarum. The results of the study may serve as basis for the development of technology for the utilization of C. microcarpa fruit waste biomass as renewable resource for industrial production of lactic acid.
\end{abstract}

Keywords: Lactobacillus plantarum, Citrofortunella microcarpa, lactic acid; waste valorization; bioconversion

\section{INTRODUCTION}

Citrofortunella microcarpa is among the most widely cultivated fruit crop in the Philippines and disposal of wastes from its processing may pose a serious environmental problem. The juice from the $C$. microcarpa fruit is extracted and used as a common flavoring agent in Philippine cuisine. It is also processed industrially into bottled or packed juice drink products, and incorporated in various consumer products including flavored soy sauce, detergents and dishwashing liquid. Data from the Philippine Statistic Authority show that in the last quarter of 2016, the country's production of $C$. microcarpa fruits reached an estimated 28.13 tons (https://psa.gov.ph/fruits-cropsbulletin/calamansi). Thus, it can be assumed that tons of wastes consisting of fruit peels and seeds 
are also produced from the industrial processing of $C$. microcarpa fruit juice.

Waste valorization, or the conversion of wastes into useful products (Arancon, Lin, Chan, Kwan, \& Luque, 2013), is an alternative management strategy to deal with the disposal challenges posed by wastes from food and agricultural industries. Because these wastes contain large amount of sugars that can be easily assimilated by microorganisms, they can be transformed into industrially important chemicals (Couto, 2008). For example, citric acid has been produced through the fermentation of banana (Karthikeyan \& Sivakumar, 2010) and orange peel (Rivas, Torrado, Torre, Converti, \& Dominguez, 2008), both through the action of Aspergillus niger while butanol has been obtained from the fermentation of apple and pear peels by Clostridium acetobutylcum (Raganati, Procentese, Oliveri, Russo, \& Marzocchella, 2016).

Among the industrial chemical that may be obtained from fruit and vegetable wastes is lactic acid. Lactic acid has numerous applications in the food and cosmetics industries as well as in the manufacture of biodegradable plastics (Datta \& Henry, 2006) and as a precursor of other chemicals and biocompatible materials with medical applications (Martinez, et al., 2013). A common route for the production of lactic acid is through the hydrolysis of lactonitrile, which is obtained from the reaction between acetaldehyde and hydrogen cyanide (Huang, Jin, Lant, \& Zhou, 2003; Martinez, et al., 2013). Lactic acid may also be produced from fermentation of various materials consisting of monosaccharides and disaccharides, starchy materials, and lignocellulosic hydrolyzates by microorganisms such as lactic acid bacteria (Martinez, et al., 2013). Previous studies have shown that lactic acid can be produced from mango peel waste by a consortium of indigenous microorganisms (Jawad, Alkarkhi, Jason, Easa, \& Nirulaini, 2013) and from potato wastewater with the aid of Rhizopus arrhizus (Huang, Jin, Lant, \& Zhou, 2003). Various microorganisms have also been shown to be effective in converting different raw materials into lactic acid. These include organisms of the following genera Carnobacterium, Enterococcus, Lactobacillus, Lactococcus, Leuconostoc, Oenococcus, Pediococcus, Streptococcus, Tetragenococcus, Vagococcus, Clostridium and Weissella (Huang, Jin, Lant, \& Zhou, 2003). Lactic acid has been produced by the following species: Streptococcus thermophilus, Lactobacillus acidophilus, Lactobacillus delbrukeii subsp bulgaricus, and Bifidobacterium bifidum (Chick, Shin, \& Ustunol, 2001) and Lactobacillus plantarum (Sreenath, Moldes, Koegel, \& Straub, 2001).

It has previously been demonstrated that the fruit peel of C. microcarpa has volatile oil and the residue left after the extraction of oil can be used in the production of pectin (Anzaldo \& Briones, 1993). The fruit peel of $C$. microcarpa contains $16.12 \mathrm{~g}$ total sugar per $100 \mathrm{~g}$ (Samonte \& Trinidad, 2013) and is therefore a potential substrate for the microbial production of lactic acid. However, to the best of our knowledge the production of lactic acid from the waste from the processing of C. $m i-$ crocarpa fruit has never been attempted. Therefore, this study was conducted to investigate the potential of C. microcarpa fruit waste as substrate for the biotechnological production of lactic acid.

\section{METHODOLOGY}

The waste materials produced after the expression of the juice from Citrofortunella microcarpa fruits were collected from food vendors inside the Central Luzon State University campus in Nueva Ecija, Philippines. The seeds were removed before the rest of the waste (rind, pulp and juice vesicles) were cleaned of unwanted materials by washing with distilled water. The cleaned waste was used in the production of hydrolysate through steam explosion by modifying a previously described method (Pumiput, Chuntranuluck, Kitpreechavanich, Punsuvon, \& Vaithanomsat, 2008). Forty grams of C. microcarpa fruit waste was steam-exploded in an autoclave at $121^{\circ} \mathrm{C}$ for $20 \mathrm{~min}$. Enough sterilized water was added to the steam-exploded waste to a volume of $1 \mathrm{~L}$, and then the mixture was heated for 20 min at $80^{\circ} \mathrm{C}$. The solid materials were separated from the supernatant with a cheese cloth. Acid hydrolysis was carried out by adding $\mathrm{HCl}$ (RCI Labscan, Thailand) to the supernatant to a final concentration of $1 \% \mathrm{v} / \mathrm{v}$ and then autoclaving the mixture at $121^{\circ} \mathrm{C}$ for $30 \mathrm{~min}$ (Umesh \& Preethi, 2014). The $\mathrm{pH}$ of the hydrolysate was adjusted to 6-6.8 using $\mathrm{CaO}$ (Sigma-Aldrich, USA) and the $\mathrm{CaSO}_{4}$ preciptate was separated from the hydrolysate through filtration (Mudaliyar, Sharma, \& Kulkarni, 2012).

Lactobacillus plantarum (BIOTECH 1223) was obtained from the National Institute of Molecular Biology and Biotechnology, University of the Philippines at Los Baños College, Laguna, Philippines. The bacterium was first grown on 
solid de Man Rogosa (MRS) medium (Scharlau, Spain) before the preparation of innoculum according to a previously described method (Umesh \& Preethi, 2014) where L. plantarum was cultivated in MRS broth prepared with the hydrolysate. After incubation for three days in a microaerophilic environment, the cell density was adjusted to $1 \times 10^{7} \mathrm{cfu} / \mathrm{mL}$ based on McFarland standard.

Fermentation mixtures were prepared by adding the L. plantarum cell suspension to the hydrolysate to produce mixtures with final concentrations of 3, 5 and $10 \%$. A negative control $(0 \%$ cell suspension) was also prepared. The hydrolysate-cell suspension mixtures were incubated for three days.

The daily lactic acid production in each of the mixture was estimated by titrating an aliquot against standardized $0.1 \mathrm{~N} \mathrm{NaOH}$ (Tehnopharmachem, India) using phenolphthalein as indicator and by applying the factor $1 \mathrm{~mL}$ of $1 \mathrm{~N} \mathrm{NaOH}$ is equivalent to $90.08 \mathrm{mg}$ of lactic acid (Sheeladevi \& Ramanathan, 2011).

The lactic acid in the fermentation broth (70 $\mathrm{mL}$ ) was recovered as calcium lactate and lactic acid crystals (Evangelista, 1994). The $\mathrm{pH}$ of the broth was adjusted to $10-11$ using calcium hydroxide (RCI Labscan, Thailand) before the temperature was raised to $80^{\circ} \mathrm{C}$ to $100^{\circ} \mathrm{C}$. The coagulated protein and cells were removed by filtration. The filtrate containing the lactic acid was added with activated carbon to remove colored components. After filtration, the filtrate was added with $5 \mathrm{ml}$ sulfuric acid (Scharlau, Spain) before undergoing a second bleacing with activated carbon. Any precipitate that formed after the addition of sulfuric acid was discarded. The excess water from the filtrate was evaporated to obtain the lactate crystals.

The production of lactate was confirmed through characterization by Fourier transform infrared spectroscopy (MB3000, Clairet Scientific, Canada) and paper chromatography using a previously described method (Al-Asady, 2012). Whatmann No. 1 served as the stationary phase while the mobile phase was 10:2 (v/v) n-butanol (Scharlau, Spain): formic acid (Sigma-Aldrich, USA) containing $0.01 \%$ bromcresol green (RCI Labscan, Thailand). Pure lactic acid (Thecnopharmachem, India) served as reference. After the development of the chromatogram, the paper was exposed to ammonia vapor. The appearance of yellow spot on a blue background indicated the presence of lactate.
Statistical analysis of the data was performed using Prism 7 (GraphPad Software, La Jolla, USA).

\section{RESULTS AND DISCUSSION}

All fermentation mixtures, except the negative control, produced lactic acid (Figure 1). The results suggest that C. microcarpa fruit waste can serve as substrate for lactic acid production by $L$. plantarum. It was observed that the production of lactic acid increased with increasing L. plantarum cell density in the fermentation mixture and with longer fermentation period. The highest amount of lactic acid was obtained in the mixture containing $10 \%$ cell suspension and incubated for three days.

The statistical analysis of the data (two-way ANOVA) also revealed a significant interaction $(\mathrm{P}<0.0001)$ between $L$. plantarum cell density and period of incubation. This implies that lactic acid production in mixtures with different cell content depends on the number of days of incubation, while the changes in lactic acid production at each day depends on the concentration of cells in the fermentation mixture.

The lactic acid produced from the fermentation of C. microcarpa fruit waste with L. plantarum was precipitated. The highest amount of crystals was obtained in the set up with $10 \%$ bacterial cell and that was incubated for three days (Figure 2). As expected, the trend in the production of lactate crystals was consistent with that observed for the bioconversion of sugars in the hydrolysate to lactic acid. Characterization of the crystals by Fourier transform infrared spectroscopy (Figure 3) revealed the presence of peaks for $\mathrm{O}-\mathrm{H}\left(3379 \mathrm{~cm}^{-1}\right), \mathrm{C}=\mathrm{O}\left(1612 \mathrm{~cm}^{-1}\right)$ and $\mathrm{C}-\mathrm{O}$ $\left(1080.06 \mathrm{~cm}^{-1}\right)$ in the spectrum that are consistent with the functional groups expected in the structure of lactate (Coates, 2000). The qualitative test by paper chromatography also showed that the crystal was a lactate (Figure 4).

Although the results do suggest that $C$. microcarpa fruit waste can be valorized as feedstock for lactic acid production, the optimum conditions for the bioconversion process have not been investigated in the present study and future investigations must focus on process optimization. For example, studies may be designed to find the optimum initial number of bacterial cell to hydrolysate ratio that would yield the highest amount of lactic acid. Such information is need- 


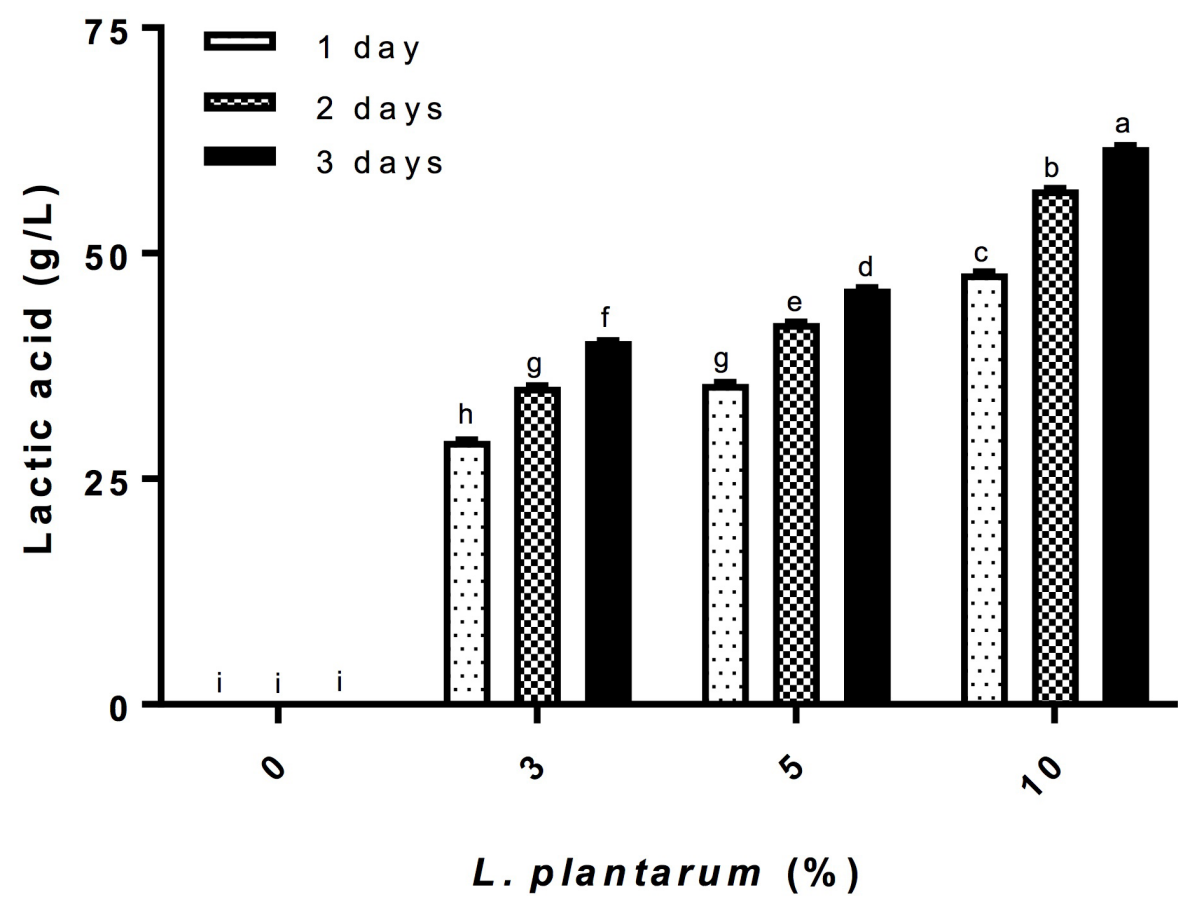

Figure 1. Lactic acid produced by Lactobacillus plantarum from Citrofortunella microcarpa fruit biomass hydrolysate. The data are presented as mean (error bar $=\mathrm{SD}$ ) of three observations. Columns labeled with the same letter are not significantly different from each other based on a two-way ANOVA followed by Tukey's multiple comparison test $(\mathrm{p}<0.0001)$. The interaction between day of incubation and L. plantarum cell density was found to be significant $(\mathrm{p}<0.0001)$

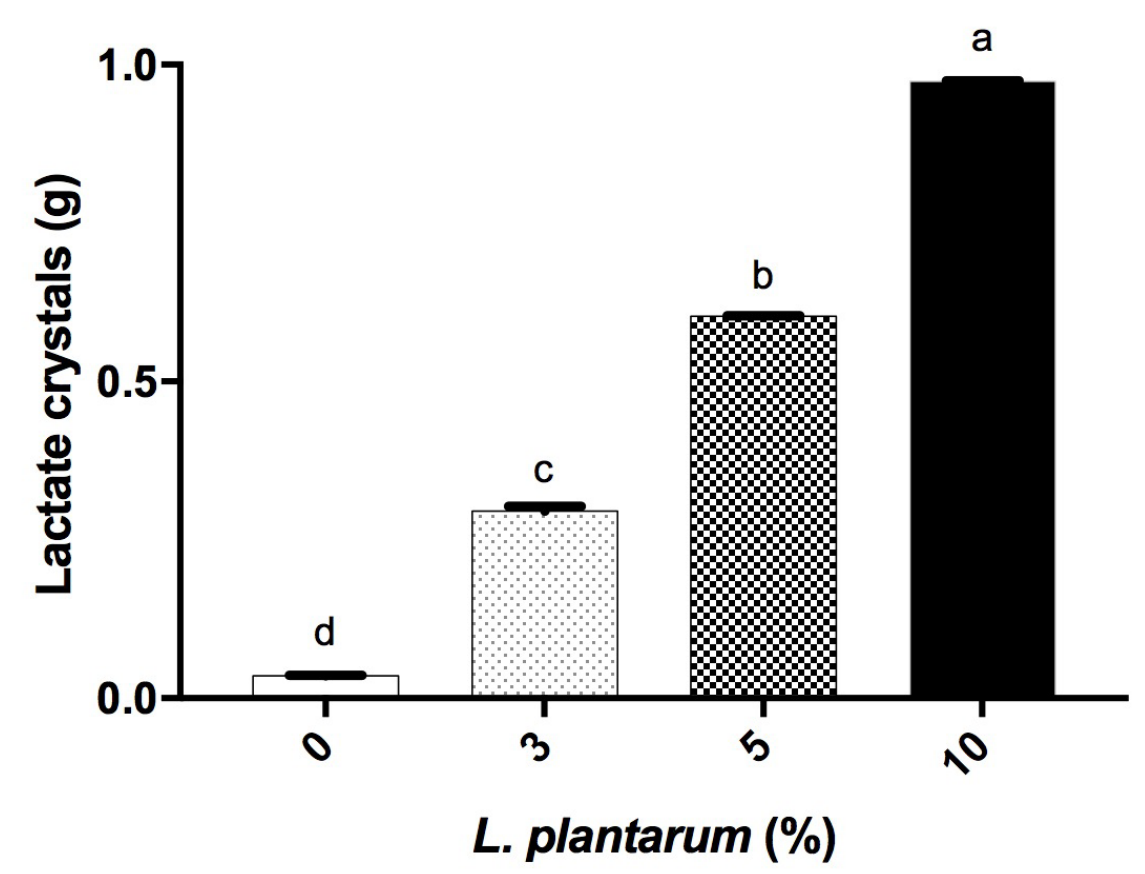

Figure 2. Lactate crystals recovered in Citrofortunella microcarpa hydrolysate after $3 \mathrm{~d}$ of fermentation with Lactobacillus plantarum. The data are presented as mean (error bar $=\mathrm{SD}$ ) of three observations. Columns labeled with the same letter are not significantly significant from each other based on one-way ANOVA followed by Tukey's multiple comparison test $(\mathrm{p}<0.0001)$ 


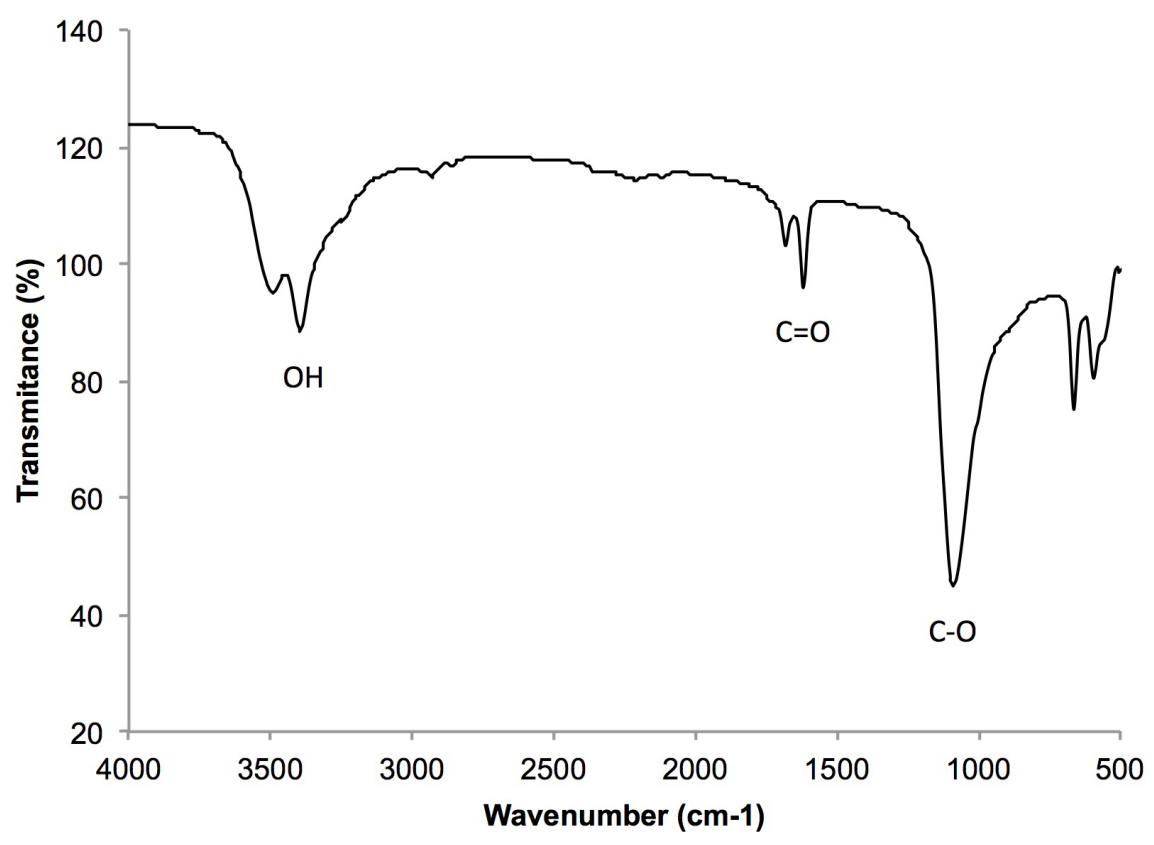

Figure 3. Infrared spectrum of lactate crystals produced by Lactobacillus plantarum from Citrofortunella microcarpa fruit waste hydrolysate

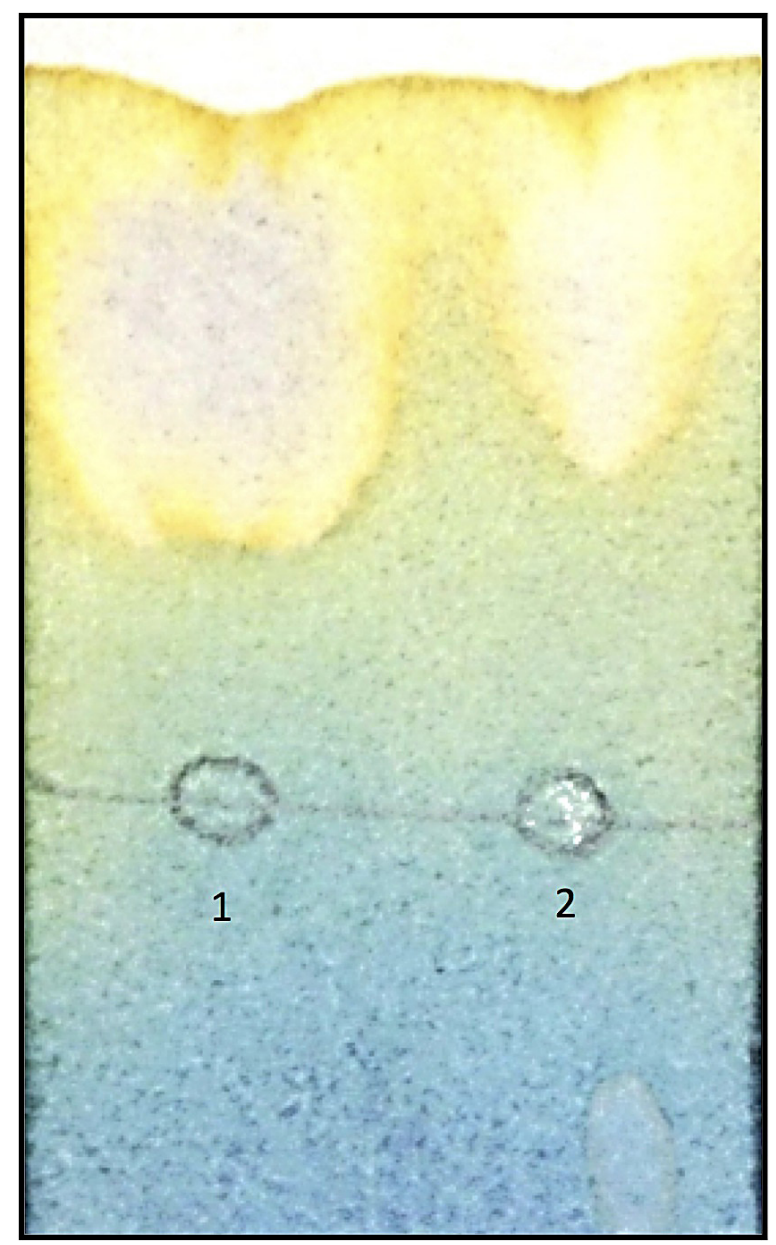

Figure 4. Representative paper chromatogram of lactic acid (1) and lactate produced by Lactobacillus plantarum from Citrofortunella microcarpa fruit waste biomass (2). The presence of yellow spot against blue background confirms the presence of lactate 
ed to ensure that the cells will not be saturated with the substrate, and that lactic acid will continuously be produced as the cell population increases. Likewise, the maximum period of incubation before the production of lactic acid ceases must be determined.

Nonetheless, the findings are consistent with previous reports about the utility of fruit and vegetable wastes as substrate for the biotechnological production of lactic acid (Al-Asady, 2012; Huang, Jin, Lant, \& Zhou, 2003; Jawad, Alkarkhi, Jason, Easa, \& Nirulaini, 2013; Sreenath, Moldes, Koegel, \& Straub, 2001) and other important chemicals, including ethanol (Karthikeyan \& Sivakumar, 2010; Raganati, Procentese, Oliveri, Russo, \& Marzocchella, 2016; Rivas, Torrado, Torre, Converti, \& Dominguez, 2008). Large amount of waste from processing of agricultural products that is generated worldwide is underutilized and discarded, despite the presence of polysaccharides in these materials that may be transformed into saleable chemicals (Van Dyk, Gama, Morrison, Swart, \& Pletschke, 2013). Use of these wastes as raw materials to produce new products is highly desirable, since it promotes the so-called zero waste economy and industrial ecology (Mirabella, Castellani, \& Sala, 2014).

Due to the large demand for biodegradable polylactic acid based materials, which are alternatives to petroleum-derived plastics, there has been an increase in interest in the production of lactic acid from cheap and renewable sources (Abdel-Rahman, Tashiro, \& Sonomoto, 2013). In 2009, the Philippines was the sole exporter of fresh fruits and juice concentrate of C. microcarpa in the world (Real \& Digal, 2010). Tons of C. microcarpa fruits are produced annually in the country and processing of these fruits will inevitably lead to the generation of tons of wastes. Using C. microcarpa wastes as feedstock for lactic acid production, which this study shows to be possible, is a green option for the management of these wastes.

\section{CONCLUSION}

Large amount of waste from the processing of C. microcarpa fruits are produced annually, creating disposal problems. This study primarily aimed to investigate the possibility of using the waste from the processing of C. microcarpa fruit waste as substrate in the production of lactic acid by L. plantarum. Lactic acid was produced from the hydrolysate of C. microcarpa fruit waste and the production of the chemical increases with increasing $L$. plantarum cell density in the fermentation broth and with increasing period of incubation. Lactic acid was recovered as crystals and characterization by FTIR spectroscopy and paper chromatography confirmed that the product was lactate. Although optimization studies have yet to be done, the results of the present study nevertheless support the mounting evidence that wastes from agriculture and food processing can be utilized for the biotechnological production of industrially important chemicals.

\section{REFERENCES}

1. Abdel-Rahman, M., Tashiro, Y., \& Sonomoto, K. 2013. Recent advances in lactic acid production by microbial fermentation processes. Biotechnology Advances, 31, 877-902.

2. Al-Asady, A.G. 2012. Production of lactic acid by a local isolate of Lactobacillus platarum using cheap starchy material hydrolysates. Pakistan Journal of Nutrition, 11(1), 88-93.

3. Anzaldo, F.E., \& Briones, A.V. 1993. Studies on the utilization of citrus wastes. NRCP Research Journal, 3(2), 115-142.

4. Arancon, R.D., Lin, C., Chan, K., Kwan, T., \& Luque, R. 2013. Advances on waste valorization: new horizons for a more sustainable society. Energy Science and Engineering, 1(2), 53-71.

5. Chick, H., Shin, H.S., \& Ustunol, Z. 2001. Growth and acid production by lactic acid bacteria and bifidobacteria grown in skim milk containing honey. Journal of Food Science, 66(3), 478-481.

6. Coates, J. 2000. Interpretation of infrared spectra, a practical approach. In: R. Meyers (Ed.), Encyclopedia of Analytical Chemistry. Chichester, UK, John Wiley \& Sons, pp. 10815-10837.

7. Couto, S.R. 2008. Exploitation of biological wastes for the production of value-added products under solid-state fermentation conditions. Biotechnology Journal, 3, 859-870.

8. Datta, R. \& Henry, M. 2006. Lactic acid: recent advances in products, processes and technologies- a review. Journal of Chemical Technology and Biotechnology, 81, 1119-1129.

9. Evangelista, R.L. 1994. Recovery and purification of lactic acid from fermentation broth by adsorption. Iowa State University, Retrospective Theses and Disserations. Paper 11252. Retrieved from Iowa State University Digital Repository: http://lib.dr.iastate.edu/cgi/viewcontent. cgi? article $=12251 \&$ context $=$ rtd 
10. Huang, L., Jin, B., Lant, P., \& Zhou, J. 2003. Biotechnological production of lactic acid integrated with potato wastewater treatment by Rhizopus arrhizus. Journal of Chemical Technology and Biotechnology, 78, 899-906.

11. Jawad, A.H., Alkarkhi, A.F., Jason, O.C., Easa, A., \& Nirulaini, N. 2013. Production of the lactic acid from mango peel waste - Factorial experiment. Journal of King Saud University - Science, 25, 39-45.

12. Karthikeyan, A. \& Sivakumar, N. 2010. Citric acid production by Koji fermentation using banana peel as a novel substrate. Bioresource Technology, 101, 5552-5556.

13. Martinez, F.C., Balciunas, E.M., Salgado, J., Gonzalez, J.D., Converti, A., \& Oliveira, R.D. 2013. Lactic acid properties, applications and production: A review. Trends in Food Science and Technology, 30, 70-83.

14. Mirabella, N., Castellani, V., \& Sala, S. 2014. Current options for the valorization of food manufacturing waste: a review. Journal of Cleaner Production, 65, 28-41.

15. Mudaliyar, P., Sharma, L., \& Kulkarni, C. 2012. Food waste management: lactic acid production by Lactobacillus species. Internationa Journal of Advanced Biological Research, 2(1), 34-38.

16. Pumiput, P., Chuntranuluck, S., Kitpreechavanich, V., Punsuvon, V., \& Vaithanomsat, P. 2008. Production process of hydrolysate from steam explosion of oil palm trunk for xylitol fermentation. Kasetsart Journal (Natural Science), 42, 73-78.

17. Raganati, F., Procentese, A., Oliveri, G., Russo, M., \& Marzocchella, A. 2016. Butanol production by fermentation of fruit residues. Chemical Engi- neering Transactions, 49, 229-234.

18. Real, R.R., \& Digal, L.N. 2010. Analyzing marketing margins and their implications in improving performance of small-scale producers in the calamansi chain in Region XI, Southern Philippines. Banwa, 7(1), 69-91.

19. Rivas, B., Torrado, A., Torre, P., Converti, A., \& Dominguez, J. 2008. Submerged citric acid fermentation on orange peel autohydrolysate. Journal of Agricultural and Food Chemistry, 56, 2380-2387.

20. Samonte, P.L., \& Trinidad, T.P. 2013. Dietary fiber, phytonutrients and antioxidant activity of common fruit peels as potential functional food ingredient. Journal of Chemistry and Chemical Engineering, 7, 70-75.

21. Sheeladevi, A., \& Ramanathan, N. 2011. Lactic acid production using lactic acid bacteria under optimized conditions. International Journal of Pharmaceutical and Biological Archives, 2(6), 1686-1691.

22. Sreenath, H.K., Moldes, A.B., Koegel, R.G., \& Straub, R.J. 2001. Lactic acid production from agricultural residues. Biotechnology Letters, 23, 179-184.

23. Umesh, M., \& Preethi, K. 2014. Fermentative utilization of fruit peel waste for lactic acid production by Lactobacillus plantarum. Indian Journal of Applied Research, 4(9), 449-451.

24. Van Dyk, J.S., Gama, R., Morrison, D., Swart, S., \& Pletschke, B.I. 2013. Food processing waste: Problems, surrent management and prospects for utilisation of the lignocellulose component through enzyme synergistic degradation. Renewable and Sustainable Energy Reviews, 26, 521-531. 